\title{
Correction to: Technical assessment and decision making for the environmental recovery of waterways and their banks: a science-based protocol
}

\author{
R. A. Silva ${ }^{1}$ - A. A. de Oliveira Afonso ${ }^{2} \cdot$ W. Francesconi ${ }^{3} \cdot$ A. M. da Silva ${ }^{1}$
}

Published online: 23 June 2018

(C) Islamic Azad University (IAU) 2018

\section{Correction to: International Journal of Environmental Science and Technology \\ https://doi.org/10.1007/s13762-018-1873-x}

The original version of this article unfortunately contained a mistake.

The spelling of the name of W. Francesconi was incorrect. The corrected name is given above.

The original article can be found online at https://doi.org/10.1007/ s13762-018-1873-x.

A. M. da Silva

amsilva@sorocaba.unesp.br

1 Department of Environmental Engineering, Institute for Science and Technology of Sorocaba, Campus Sorocaba, Sao Paulo State University, 511, Tres de Marco Avenue, Altos da Boa Vista, Sorocaba, SP 18087-180, Brazil

2 Sao Paulo State Company for Environmental Technology (CETESB), 820, Americo de Carvalho Avenue, Jardim Europa, Sorocaba, SP, 18045-000, Brazil

3 International Center for Tropical Agricultural (CIAT), Lima, Peru 